\title{
Synthesis and adsorption properties of ZIF-76 isomorphs
}

\author{
David Peralta ${ }^{\text {a, b }}$, Gérald Chaplais ${ }^{\text {a }}$, Angélique Simon-Masseron ${ }^{\text {a }}$, Karin Barthelet ${ }^{\text {b }}$ \\ and Gerhard D. Pirngruber ${ }^{b}$ \\ ${ }^{a}$ Equipe Matériaux à Porosité Controlée (MPC), Institut de Science des Matériaux de \\ Mulhouse (IS2M), LRC CNRS 7228, UHA, ENSCMu, 3 rue Alfred Werner, 68093 Mulhouse \\ Cedex, France. \\ ${ }^{\mathrm{b}}$ IFP Energies nouvelles BP3, Site of Lyon, 69360 Solaize, France.
}

Corresponding author:

Gerhard D. Pirngruber

IFP Energies nouvelles, Catalysis and Separation Division

Rond Point échangeur de Solaize, 69390 Solaize, France

Email: gerhard.pirngruber@ifpen.fr,

Tel. + 33437702733 ,

Fax +33437702060 


\begin{abstract}
:
ZIF-76, $\mathrm{Zn}(\operatorname{Im})_{\mathrm{x}}(5-\mathrm{ClbIm})_{\mathrm{y}}(\mathrm{Im}=$ imidazolate, 5-ClbIm=5-chlorobenzimidazolate $)$, is, among the known ZIF structures, one of the few materials that combine a relatively large pore aperture with a large pore volume. Moreover, it is thermally stable up to $400{ }^{\circ} \mathrm{C}$ and can be stored under ambient atmosphere without undergoing a measurable degradation. ZIF-76, therefore, appears to be an interesting material for applications in adsorption and separation. The published synthesis protocol leads to very low yields and is, thus, not applicable on a larger scale [1]. In this work, we have succeeded in preparing ZIF-76 in suitable yields by changing the solvent and adding $\mathrm{NaOH}$ to the synthesis mixture. The addition of the base increases the yield and leads to smaller crystal sizes, by favoring nucleation over crystal growth. By using the same synthesis strategy, four new isomorphs of ZIF-76 were obtained, with different substituents on the benzimidazole ligand $\left(\mathrm{Me}, \mathrm{Br}\right.$ and $\mathrm{NO}_{2}$ ) and different metal sources (Co and $\mathrm{Zn})$. All the samples were tested in the adsorption and separation of $\mathrm{CO}_{2} / \mathrm{CH}_{4}$ in order to highlight the influence of the linker and of the metal center on the adsorption/separation properties.
\end{abstract}

KEYWORDS: MOF, ZIF, LTA, benzimidazole, carbon dioxide

\title{
1. INTRODUCTION
}

In the last years, the Metal-Organic Frameworks (MOFs) have received a lot of attention because of their large porosity, and structural diversity [2-4]. It has been shown that these compounds are good candidates for adsorption and catalytic processes [5-7]. The hybrid nature of the materials fuelled expectations that it will be possible to discover new behaviours in separation and catalysis. But the hybrid character of these compounds, which is at the 
origin of their structural diversity, also implies that the thermal stability of this class of materials is limited. Only a minority of the known MOFs maintain their structure at temperatures above $300{ }^{\circ} \mathrm{C}$.

The Zeolitic Imidazolate Frameworks (ZIFs) constitute a new subfamily of MOFs $[1,8]$. ZIFs are synthesised from imidazolate ligands coordinated to bivalent metal cations, usually $\mathrm{Zn}^{2+}$ or $\mathrm{Co}^{2+}$. The $\mathrm{M}-\mathrm{Im}-\mathrm{M}$ angle $(\mathrm{M}=$ metal $)$ is similar to the Si-O-Si angle observed in zeolites. The nature and the size of ligands (imidazolate and/or benzimidazolate) lead to ZIFs with zeolite topology, but with bigger pores than their inorganic analogues. The resulting structures are in general very stable: some of ZIFs are thermally stable up to $400{ }^{\circ} \mathrm{C}[1,9,10]$. ZIF-76 is one of the most interesting structures published by the Yaghi's group. ZIF-76 is composed of zinc and a mixture of imidazole (Im) and 5-chlorobenzimidazole (5-ClbIm) as ligands. The resulting structure displays LTA topology, but with bigger pores than those of related non-hybrid zeolitic materials (Figure 1).

Application of the ZIF-76 synthesis protocol described by Yaghi's group using a larger amount of reactants gives a low yield. In order to obtain gram scale quantities of ZIF-76 for adsorption and separation measurements, we first had to optimize the synthesis procedure on a small scale. To improve the yield of the synthesis, we investigated several parameters such as the solvent mixture, the duration, the temperature and the addition of a base as a catalyst. An obvious role of a base in the synthesis of $\mathrm{ZIF} / \mathrm{MOF}$ materials is the deprotonation of the organic ligand [11]. Bases are often employed in the room temperature synthesis of ZIFs/MOFs. The addition of a base was recognized as an opportunity to accelerate the synthesis, obtain high yields and crystals in the nanometer size range, which is more attractive for most applications [12]. However, several studies of the synthesis of MOF-5 show that materials prepared by the base route at room temperature possess a lower crystallinity and more defects compared to MOF-5 samples prepared under solvothermal conditions $[13,14]$. 
In this work, we investigate in detail the influence of adding a base to the synthesis mixture of ZIF materials. We highlight the link between basicity, duration of synthesis and morphology of the final product, using a solvothermal synthesis route. After optimization of the synthesis protocol, we describe the preparation of several isomorphs of the ZIF-76 (LTA) involving imidazole $(\mathrm{Im})$ and derivatives of benzimidazole $(5-\mathrm{XbIm}$ where $\mathrm{X}$ is either a chloro, bromo, methyl or nitro group) as organic linker and zinc or cobalt as metal node. All these materials were then tested in the adsorption and separation of $\mathrm{CO}_{2} / \mathrm{CH}_{4}$ in order to evaluate the influence of the ligand and of the metal center on the interaction between adsorbate and framework [15-17].

\section{EXPERIMENTAL SECTION}

\section{Reactants and solvents}

All the reactants and solvents were used without further purification. The metal sources, cobalt nitrate hexahydrate $\left(\mathrm{Co}\left(\mathrm{NO}_{3}\right)_{2} \cdot 6 \mathrm{H}_{2} \mathrm{O}, 98.0 \%\right)$ and zinc nitrate hexahydrate $\left(\mathrm{Zn}\left(\mathrm{NO}_{3}\right)_{2} \cdot 6 \mathrm{H}_{2} \mathrm{O}, 99.0 \%\right)$ were purchased from Alfa Aesar. Organic compounds were supplied by Sigma Aldrich for imidazole (Im, 99.5\%), 5-chlorobenzimidazole (5-ClbIm, 96.0\%), 5-methylbenzimidazole (5-MebIm, 98\%), by Maybridge for 5-bromobenzimidazole (5-BrbIm, 97.0\%) or by Acros Organics for 5-nitrobenzimidazole (5-NibIm, 98.0\%). The solvents, N,N-dimethylformamide (DMF, 99.0\%) and N,N-diethylformamide (DEF, 99.0\%) were provided by Alfa Aesar.

\section{Synthesis}

Initial synthesis conditions for the preparation of ZIF-76 are given in the literature by Yaghi's group: $2.25 \times 10^{-5} \mathrm{~mol}$ imidazole (Im) and $1.13 \times 10^{-5} \mathrm{~mol} 5$-chlorobenzimidazole (5ClbIm) were mixed together in $0.3 \mathrm{ml}$ of DMF [1]. $1.12 \times 10^{-5}$ mol of zinc nitrate was added 
to this solution. A vial of $0.5 \mathrm{ml}$ was loaded with the mixture and was heated in an oven at 65 ${ }^{\circ} \mathrm{C}$ for 5 days.

The above-mentioned literature protocol was optimized by modifying the reaction parameters : temperature, duration, concentration of the reactants, nature of solvent and concentration of the base. The different synthesis conditions are compiled in Table 1. As it will be explained in detail in the results section, the optimal synthesis conditions are those of entry 10 in Table 1: $17.25 \times 10^{-4} \mathrm{~mol}$ imidazole $(\mathrm{Im})$ and $8.66 \times 10^{-4} \mathrm{~mol}$ 5-chlorobenzimidazole were mixed in $743 \times 10^{-4} \mathrm{~mol}$ of DMF and $516 \times 10^{-4} \mathrm{~mol}$ of DEF. $8.59 \times 10^{-4} \mathrm{~mol} \mathrm{Zn}\left(\mathrm{NO}_{3}\right)_{2} \cdot 6 \mathrm{H}_{2} \mathrm{O}$ were added to this solution. In the optimized protocol, $12.96 \times 10^{-4} \mathrm{~mol}$ of a solution of $\mathrm{NaOH}(2.5 \mathrm{~mol} / \mathrm{L})$ were added in addition. All the syntheses were performed in $23 \mathrm{ml}$ polypropylene containers, which were heated in an oven at $90{ }^{\circ} \mathrm{C}$ for 5 days. The yields were calculated by dividing the mass of desolvated (guest free) materials by the theoretical mass of product, calculated from the amount of metal precursor.

For the preparation of modified ZIF-76 materials, $\mathrm{Zn}(\operatorname{Im})(5-\mathrm{Meb} \operatorname{Im}), \mathrm{Zn}(\operatorname{Im})(5-$ BrbIm), $\mathrm{Zn}(\operatorname{Im})(5-\mathrm{Nib} \operatorname{Im}), \mathrm{Co}(\operatorname{Im})(5-\mathrm{Clb} \operatorname{Im})$, the reaction conditions were the same as in the optimized protocol mentioned above. Either 5-ClbIm was substituted by one of the other ligands or $\mathrm{Zn}\left(\mathrm{NO}_{3}\right)_{2} \cdot 6 \mathrm{H}_{2} \mathrm{O}$ was replaced by $\mathrm{Co}\left(\mathrm{NO}_{3}\right)_{2} \cdot 6 \mathrm{H}_{2} \mathrm{O}$.

\section{Characterization}

XRD, SEM, NMR and thermal analysis

All samples were characterized by X-ray diffraction using a STOE STADI-P diffractometer equipped with a curved monochromator $\mathrm{Ge}(111)$ and a linear position sensitive detector in the $3-50^{\circ}(2 \theta)$ range on transmission $\mathrm{CuK} \alpha 1(\lambda=0.15406 \mathrm{~nm})$.

Morphology and size of the crystals were determined by scanning electron microscopy using a Philips XL 30 microscope equipped with a field electron gun. 
Thermogravimetric measurements were performed on a Netzsch TG 209 F1 Iris apparatus with a heating rate of $5{ }^{\circ} \mathrm{C} / \mathrm{min}$ from room temperature to $800{ }^{\circ} \mathrm{C}$.

${ }^{1} \mathrm{H}$ NMR spectra were carried out on a Bruker 400 UltraShield $^{\mathrm{TM}}$ by using tetramethylsilane as standard. Typically, around $3 \mathrm{mg}$ of ZIF-76 materials are digested in a solution of $\mathrm{DCl} / \mathrm{D}_{2} \mathrm{O} 35 \%$ wt dispersed in DMSO- $\mathrm{d}_{6}$.

\section{Adsorption and separation measurements}

$\mathrm{N}_{2}$ isotherms were recorded at $77 \mathrm{~K}$ on a Micromeritics ASAP 2420 apparatus, after degassing at $250{ }^{\circ} \mathrm{C}$ for $12 \mathrm{~h}$. The specific surface area was deduced from the BET model, in the pressure range of $\mathrm{P} / \mathrm{P}^{\circ}=0.002-0.05$. The pore volume was determined by the $\mathrm{t}$-plot method. Isotherms of $\mathrm{CO}_{2}$ and $\mathrm{CH}_{4}$ were performed on a Rubotherm magnetic suspension balance. In a typical adsorption experiment, about $1-2 \mathrm{~g}$ of sample was placed in a basket suspended by a permanent magnet through an electromagnet. The cell in which the basket is housed is then closed and the sample is heated under high vacuum to $240{ }^{\circ} \mathrm{C}$ for $3 \mathrm{~h}$. The $\mathrm{CO}_{2}$ and $\mathrm{CH}_{4}$ isotherms were then recorded at $30{ }^{\circ} \mathrm{C}$. Helium was used to determine the volume of sample and sample holder, which is necessary to correct the measured apparent mass for buoyancy effects.

The separation of $\mathrm{CO}_{2}$ and $\mathrm{CH}_{4}$ was evaluated by breakthrough measurements. 1.5 - 2 $\mathrm{g}$ of powder sample were placed in a stainless steel column with an inner diameter of $7 \mathrm{~mm}$ and a length of $10 \mathrm{~cm}$, which was placed in furnace. The sample was heated in a flow of 0.5 $\mathrm{NL} / \mathrm{h} \mathrm{He}$ to $240{ }^{\circ} \mathrm{C}$ and kept at this temperature for $3 \mathrm{~h}$ before cooling down to $30{ }^{\circ} \mathrm{C}$. The breakthrough experiment was started by switching from He to an equimolar gas mixture of $\mathrm{CO}_{2} / \mathrm{CH}_{4}$. The breakthrough was followed by a mass spectrometer [18]. The adsorbed quantities $\mathrm{Q}_{\mathrm{ads}}$ were calculated by a mass balance. The $\mathrm{CO}_{2} / \mathrm{CH}_{4}$ selectivity $\mathrm{S}$ was obtained from the equation $\mathrm{S}=\left(\mathrm{Q}_{\mathrm{CO} 2} / \mathrm{p}_{\mathrm{CO} 2}\right) /\left(\mathrm{Q}_{\mathrm{CH} 4} / \mathrm{p}_{\mathrm{CH} 4}\right)$. 


\section{RESULTS}

\section{Optimization of the synthesis of ZIF-76}

Table 1 summarizes the synthesis conditions which were tested in order to optimize the synthesis of ZIF-76. The XRD patterns of the products are shown in the supporting information files (S1). In order to investigate the influence of the nature of solvent on the crystallinity, two syntheses were carried out (samples 1 and 2): the first one using DMF as unique solvent and the second one using a mixture of DMF/DEF $(1: 1 ; \mathrm{V}: \mathrm{V})$. The resulting XRD patterns are shown in Figure 2. Sample 2, which was synthesised in a mixture of DMF/DEF, appears more crystalline than sample 1, prepared in DMF. However, the yield remains low: $20.5 \%$ and $14.5 \%$ for samples 1 and 2 respectively.

In order to determine the roles of the temperature and of the concentration of reactants, the results for synthesis runs 2 to 5 have to be examined. The four syntheses were performed in a mixture of DMF/DEF $(1: 1 ; \mathrm{V}: \mathrm{V})$. The reactant concentrations were either those used by Yaghi's group or twice higher. The temperature was either 70 or $90{ }^{\circ} \mathrm{C}$. A comparison of runs 2 and 4 (respective yields: $14.5 \%$ and $37.2 \%$ ) as well as runs 3 and 5 (respective yields: $0.0 \%$ and $27.5 \%$ ), indicates that the best yields are obtained at the higher temperature (90 ${ }^{\circ} \mathrm{C}$ ) and at the lower reactant concentration. A high dilution of the reactants is, however, undesirable for syntheses at medium/large scale because it increases the required reactor volume.

In order to increase the yield at high reactant concentration, we investigated the influence of increasing the duration of the synthesis and of adding a base to the synthesis mixture. Two series of four syntheses (runs 5 to 8 and runs 9 to 12) were prepared with the same reactant concentration (twice higher than proposed by Yaghi's group) at $90{ }^{\circ} \mathrm{C}$, but two different durations (5 or $30 \mathrm{~d})$. The basicity of the solution was modulated by adding a 
solution of $\mathrm{NaOH}(2.5 \mathrm{~mol} / \mathrm{L})$. The amount of base, expressed as the ratio $\mathrm{B} / \mathrm{L}$ (base/ligand), i.e. the number of moles of $\mathrm{NaOH}$ divided by the total number of moles of imidazole ligands $(\operatorname{Im}+\mathrm{Clb} \operatorname{Im})$, was fixed at $0,0.5,1$ and 2 . The ratios $\mathrm{B} / \mathrm{L}=1$ and 2 led to a product with a low crystallinity $(B / L=1)$ or a product that was not pure $(B / L=2)$, see Figure 3 . It is, therefore, preferable to limit the addition of $\mathrm{NaOH}$ to a value of $\mathrm{B} / \mathrm{L}=0.5$.

The yield of the synthesis without $\mathrm{NaOH}$ (synthesis 5 and 9) increases with time from $27.5 \%$ (5 days) to $73 \%$ (30 days). The yield of the analogue synthesis with a ratio of $\mathrm{B} / \mathrm{L}=$ 0.5 increases from $50.6 \%$ after 5 days to $71.9 \%$ after 30 days. The addition of a base increases the yield of the synthesis by a factor of 1.8 after 5 days. The positive effect of the base on the yield disappears at longer synthesis duration (30 d).

To be sure that $\mathrm{NaOH}$ does not recrystallize in the pore of the ZIF-76, the products of syntheses 9 and 10 were analysed by $\mathrm{N}_{2}$ adsorption measurements. The isotherms of the two materials are very close. The pore volume of compounds synthesized with and without addition of $\mathrm{NaOH}$ is 0.59 and $0.56 \mathrm{~mL} / \mathrm{g}$, respectively. Therefore, the addition of $\mathrm{NaOH}$ does not influence the porosity of the materials.

The morphologies of ZIF-76 materials were investigated by SEM (see Figure 4; more SEM pictures are shown in the supporting information S2). The SEM pictures confirmed that the addition of a large quantity of base $(\mathrm{B} / \mathrm{L}=1$ and 2$)$ induced the formation of impurities (see the zooms for samples 11 and 12 in Figure $4 \mathrm{c}$ and d). Table 2 reports the average values of the crystal size observed after 5 and 30 days (full crystal size distributions are given in the supporting information). The crystals synthesised without any addition of $\mathrm{NaOH}(\mathrm{B} / \mathrm{L}=0)$ are much bigger than the others. Moreover, we observe a strong crystal growth between 5 and 30 days in the absence of $\mathrm{NaOH}$, but no clear evolution of the crystal size with time when $\mathrm{NaOH}$ is present. 


\section{Synthesis and characterization of news isomorphs of ZIF-76}

A main characteristic of hybrid materials is the possibility to tune the composition of materials by changing the metal source or the organic functional group without any modification of the topology of the framework. We used our optimized protocol of synthesis in order to obtain several isomorphs of ZIF-76, using two different metal sources (zinc or cobalt) and three new benzimidazole ligands containing a bromo, methyl or nitro group in position 5. The materials were analysed by XRD and compared to the experimental and theoretical patterns of ZIF-76 (see Figure 5). The XRD patterns of the isomorphous structures are very close to the original pattern of ZIF-76. XRD reveals that all the compounds crystallize in the same space group with similar unit cell parameters.

According to the thermal analysis shown in Figure 6, the isomorphs are stable to 400 ${ }^{\circ} \mathrm{C}$ under helium atmosphere, except for ZIF-76 synthesised with 5-nitrobenzimidazole. This high thermal stability allows a direct activation of the compound by heating to $250{ }^{\circ} \mathrm{C}$ for 6 hours without any prior solvent exchange. The ZIF-76 synthesised with 5-nitrobenzimidazole is air sensitive. It loses crystallinity already at a temperature of $90{ }^{\circ} \mathrm{C}$. Due to the poor thermal stability of this material, the activation procedure is particular. The as made compound was immediately immerged in methanol after filtration and heated at $65^{\circ} \mathrm{C}$ for two weeks before activation at $90^{\circ} \mathrm{C}$.

The ratio between imidazole and the substituted benzimidazole ligand was obtained by NMR measurements (Figure 7 and Table 3) for each material. In all cases, the $\mathrm{Im} / \mathrm{XbIm}$ ratio is lower than the value of 3 that was reported by Yaghi's group. Curiously, the Im/XbIm ratio decreases when the size of the organic functional group increases. Steric effects cannot explain this trend. In spite of the beneficial influence of DEF in the synthesis of ZIF materials, NMR indicates that DEF is not present in the pores of the ZIF-76 isomorphs, while DMF is, with the exception of ZIF-76-NibIm. The absence of DMF in the porosity of the ZIF-76 
synthesized with 5-nitrobenzimidazole confirms that the solvent exchange by methanol was very efficient.

The compounds were analyzed by nitrogen adsorption in order to evaluate the porosity of all isomorphs. All nitrogen isotherms are of type I. The specific surface areas and pore volumes are summarized in Table 4. Except for the isomorph based on 5-NibIm, all materials possess a specific surface area above $1000 \mathrm{~m}^{2} \cdot \mathrm{g}^{-1}$. We assume that the low porosity of the $\mathrm{Zn}(\operatorname{Im})_{1.05}(5-\mathrm{NibIm})_{0.95}$ is due to a partial destruction of the framework because contact of the sample with moisture could not be entirely avoided. It is, however, possible that a different orientation of the nitrobenzimidazole ligand also contributes to the loss of pore volume.

\section{Adsorption and separation results of $\mathrm{CO}_{2}$ and $\mathrm{CH}_{4}$}

The five isomorphous materials were tested in the adsorption and separation of $\mathrm{CO}_{2} / \mathrm{CH}_{4}$. The adsorption isotherms of $\mathrm{CO}_{2}$ and $\mathrm{CH}_{4}$ at $303 \mathrm{~K}$ are shown in Figure 8 (a zoom on the low pressure part of the isotherms is shown in the supporting information S3). The high pressure part of the isotherm is governed by the available pore volume, while the initial slope depends on the specific surface area and the affinity between adsorbate and adsorbent [19]. All the isomorphs have a lower $\mathrm{CO}_{2}$ uptake than the "parent" $\mathrm{Zn}(\operatorname{Im})_{1.25}(5-\mathrm{ClbIM})_{0.75}$ material. Since pore volume, surface and affinity change at the same time, it is not straightforward to identify a clear trend within the group of substituents chloro, bromo and methyl. We can, however, perceive in Figure 8 that the material synthesized with 5-NibIm has a higher initial slope than expected from its surface area. The high polarity of the $\mathrm{NO}_{2}$ functional group induces a strong interaction between the ZIF-76 network and $\mathrm{CO}_{2}$ molecules and, therefore, leads to an isotherm that is more concave. 
The adsorption of $\mathrm{CH}_{4}$, on the other hand, is only governed by non specific interactions. Therefore, the $\mathrm{NO}_{2}$ functional group does not have an apparent influence on the concavity of the $\mathrm{CH}_{4}$ isotherm (as compared to chloro, bromo or methyl).

It is possible to estimate the co-adsorption selectivity of a $\mathrm{CO}_{2} / \mathrm{CH}_{4}$ mixture from the Henry constants (the initial slopes) of the respective single component isotherms. These values are given in Table 4. A direct measurement of co-adsorption selectivity by, for example, a breakthrough experiment is, however, more reliable. Figure 9 shows, as an example, the breakthrough curve of an equimolar $\mathrm{CO}_{2} / \mathrm{CH}_{4}$ mixture over the parent $\mathrm{Zn}(\mathrm{Im})_{1.25}(5-\mathrm{ClbIm})_{0.75}$. The curve of $\mathrm{CH}_{4}$ exhibits a characteristic "roll-up", due to replacement of adsorbed $\mathrm{CH}_{4}$ by $\mathrm{CO}_{2}$, when the adsorption front of $\mathrm{CO}_{2}$ advances through the column. The $\mathrm{CO}_{2} / \mathrm{CH}_{4}$ selectivities obtained from the breakthrough experiments are summarized in the Table 4. They agree fairly well with the ratios of the Henry constants. The substitution of chloro by bromo or methyl in the benzimidazole ligand or the replacement of $\mathrm{Zn}$ by Co as the metal node does not have a measurable impact on the separation selectivity. Only the nitrobenzimidazole ligand leads to a significantly higher selectivity than the parent sample.

\section{DISCUSSION}

\section{The role of solvent and base in the synthesis of ZIF-76}

In MOF/ZIF synthesis, it is commonly admitted that the solvent is not only to dissolve the reactants; it can also serve as a structure directing agent [11]. In the synthesis of the ZIF76, the addition of a second solvent (DEF) increases the crystallinity of the final material. Surprisingly, NMR analyses show that hardly any DEF is present in the porosity of the materials, which excludes a structure directing role. We suspect that the role of DEF is to slow down the kinetics of crystallization (the yield in DEF mixtures is lower), maybe because 
it solubilizes the reactants less well, thereby improving the quality of the crystals that are formed.

Many synthesis protocols of MOF/ZIF materials use a base to promote the reaction (usually at room temperature). In our case, the main role of the base is to deprotonate the imidazole ligands. This favors the bond formation between metal cation and imidazolate and thereby favors nucleation. As a consequence, the imidazole nutrients are consumed more quickly, the yield at short synthesis times increases and small crystals are obtained. The addition of a controlled quantity of $\mathrm{NaOH}$ allows to double the reactant concentration and to obtain a satisfactory yield in five days. Moreover, this optimized protocol could be scaled up to a volume of $1 \mathrm{~L}$ without any loss of yield or crystallinity and could be extended to the synthesis of several isomorphs of ZIF-76.

\section{Stability of the ZIF-76 isomorphs}

Except for the material synthesized using 5-NibIm, all the isomorphs display a high porosity and good thermal stability. The high thermal stability allows to easily activate the materials without prior solvent exchange. In the case of the ZIF-76-NibIm, a solvent exchange of the DMF by $\mathrm{MeOH}$ allows to completely remove DMF of the porosity and makes it possible to activate material in spite of its low thermal stability. The low thermal stability of the ZIF-76 with 5-NibIm could be explained by the $\mathrm{pK}_{\mathrm{a}}$ of the ligand. The higher the electrophilicity of the organic group is, the lower is the $\mathrm{pK}_{\mathrm{a}}$ of the ligand and, consequently, the metal-imidazolate bond becomes weaker. 5-NibIm exhibits the lowest $\mathrm{pK}_{\mathrm{a}}$ of the ligands used in this study $\left(\mathrm{pK}_{\mathrm{a}}(5-\mathrm{NibIm})=4.17, \mathrm{pK}_{\mathrm{a}}(5-\mathrm{ClbIm})=4.86, \mathrm{pK}_{\mathrm{a}}(5-\mathrm{MebIm})=5.81\right)$ \{Brown, 2006128 /id;Brown, 2006129 /id\}.

\section{Discussion of the adsorption behavior of ZIF-76 isomorphs}

Organic ligands with highly polar functional groups considerably increase the interactions between framework and $\mathrm{CO}_{2}$ molecules but not with $\mathrm{CH}_{4}$. ZIF-76 materials 
prepared with chloro, methyl and bromo groups show a similar selectivity of $2.5+/-0.2$. This value is characteristic of nonpolar adsorbents, like activated carbons or a dealuminated zeolite Y \{Wilson, 1983125 /id;Ritter, 1987126 /id;Buss, 1998127 /id\}. Only the ZIF-76 material synthesized with 5 -NibIm is more selective for the $\mathrm{CO}_{2} / \mathrm{CH}_{4}$ separation. The high polarity induced by the $\mathrm{NO}_{2}$ functional group specifically increases the interaction between the $\mathrm{CO}_{2}$ molecules and the ZIF-76 framework, but does not affect the adsorption of $\mathrm{CH}_{4}$. As a consequence, the selectivity of this isomorph is nearly 3 times higher than for the other ZIF76 samples. Our results are in line with data published by Yaghi et al. who tested several isomorphs of ZIF materials with GME topology using benzimidazole ligands substituted by chloro, methyl, bromo, nitro or hydrogen moieties [16]. The results show that the addition of chloro, methyl or bromo functional groups does not influence the $\mathrm{CO}_{2} / \mathrm{CH}_{4}$ selectivity; only the nitro group could increase the $\mathrm{CO}_{2} / \mathrm{CH}_{4}$ selectivity. However, we mentioned above that the use of the nitro group decreases the $\mathrm{pKa}$ of the benzimidazole ligand and decreases the stability of the material. An amino-substituted benzimidazole could be an attractive alternative because it combines a high polarity with a high pKa of the ligand (pKa of 5aminobenzimidazole $=6.11$, and, therefore, according to our theory, a higher stability of the ZIF framework [15,20]. The positive effect of amino-functionalization of MIL-53(Al) type material on the $\mathrm{CO}_{2} / \mathrm{CH}_{4}$ separation was already shown by Couck et al. [25]. Our future work will aim to synthesize the ZIF-76 isomorph built from 5-aminobenzimidazole and to evaluate its separation properties.

Our results further show that choice of the transition metal center $\left(\mathrm{Zn}^{2+}\right.$ or $\left.\mathrm{Co}^{2+}\right)$ does not change the separation selectivity of the material. The metal center is too distant from the adsorbate to have an influence on the $\mathrm{CO}_{2}$ adsorption. This result was already predicted by Monte Carlo simulations [26]. 


\section{CONCLUSIONS}

In this paper, we present an optimized procedure to obtain ZIF-76 and four news isomorphs of ZIF-76 in high yield and a short synthesis time. The key is the addition of the base $\mathrm{NaOH}$ to the mixture, which increases the yield and accelerates the crystal formation. The base promotes the nucleation phase and inhibits crystal growth. Crystals obtained by the abovedescribed protocol are 50 to 200 times smaller than those obtained without the addition of any base.

In the separation of $\mathrm{CO}_{2} / \mathrm{CH}_{4}$, only the isomorph synthesized with the 5-nitrobenzimidazole presents an improved selectivity. This is attributed to its strong polarity. Unfortunately, this is accompanied by a weak stability of the material, presumably caused by the low pKa of 5nitrobenzimidazole. A better compromise between selectivity and stability could probably be achieved by using imidazole ligands with polar, but more basic substituents, for example 5aminobenzimidazole. Finally, adsorption and separation tests of $\mathrm{CO}_{2}$ and $\mathrm{CH}_{4}$ show that the metal source (cobalt or zinc) does not have a significant influence on the adsorption properties.

\section{Reference List}

[1] R. Banerjee, A. Phan, B. Wang, C. Knobler, H. Furukawa, M. O'Keeffe, and O.M. Yaghi, Science, 319 (2008) 939-943.

[2] M. Eddaoudi, J. Kim, N. Rosi, D. Vodak, J. Wachter, M. O'Keeffe, and O.M. Yaghi, Science, 295 (2002) 469-472.

[3] G. Férey, Chem. Soc. Rev., 37 (2008) 191-214.

[4] J.L.C. Rowsell and O.M. Yaghi, Microporous Mesoporous Mater., 73 (2004) 3-14.

[5] L. Alaerts, C.E.A. Kirschhock, M. Maes, M.A. van der Veen, V. Finsy, A. Depla, J.A. Martens, G.V. Baron, P.A. Jacobs, J.E.M. Denayer, and D.E. De Vos, Angew. Chem. Int. Ed., 46 (2007) 4293-4297. 
[6] M. Hartmann, S. Kunz, D. Himsl, O. Tangermann, S. Ernst, and A. Wagener, Langmuir, 24 (2008) 8634-8642.

[7] D. Farrusseng, S. Aguado, and C. Pinel, Angew. Chem. Int. Ed., 48 (2009) 7502-7513.

[8] K.S. Park, Z. Ni, A.P. Cote, J.Y. Choi, R.D. Huang, F.J. Uribe-Romo, H.K. Chae, M. O'Keeffe, and O.M. Yaghi, Proc. Natl. Acad. Sci. U. S. A., 103 (2006) 10186-10191.

[9] J.J. Low, A.I. Benin, P. Jakubczak, J.F. Abrahamian, S.A. Faheem, and R.R. Willis, J. Am. Chem. Soc., 131 (2009) 15834-15842.

[10] K.A. Cychosz and A.J. Matzger, Langmuir, 26 (2010) 17198-17202.

[11] Y.Q. Tian, Y.M. Zhao, Z.X. Chen, G.N. Zhang, L.H. Weng, and D.Y. Zhao, Chem. Eur. J., 13 (2007) 4146-4154.

[12] L. Huang, H. Wang, J. Chen, Z. Wang, J. Sun, D. Zhao, and Y. Yan, Microporous and Mesoporous Mater., 58 (2003) 105-114.

[13] J. Li, S. Cheng, Q. Zhao, P. Long, and J. Dong, Int. J. Hydrogen Energy, 34 (2009) 1377-1382.

[14] U. Ravon, M. Savonnet, S. Aguado, M.E. Domine, E. Janneau, and D. Farrusseng, Microporous Mesoporous Mater., 129 (2010) 319-329.

[15] A. Torrisi, R.G. Bell, and C. Mellot-Draznieks, Cryst. Growth Des., 10 (2010) 28392841.

[16] R. Banerjee, H. Furukawa, D. Britt, C. Knobler, M. O'Keeffe, and O.M. Yaghi, J. Am. Chem. Soc., 131 (2009) 3875.

[17] H.X. Deng, C.J. Doonan, H. Furukawa, R.B. Ferreira, J. Towne, C.B. Knobler, B. Wang, and O.M. Yaghi, Science, 327 (2010) 846-850.

[18] Y. Belmabkhout, G. Pirngruber, E. Jolimaitre, and A. Methivier, Adsorption, 13 (2007) 341-349.

[19] Q. Yang, C. Zhong, and J.F. Chen, J. Phys. Chem. C, 112 (2008) 1562-1569.

[20] T.N. Brown and N. Mora-Diez, J. Phys. Chem. B, 110 (2006) 9270-9279.

[21] T.N. Brown and N. Mora-Diez, J. Phys. Chem. B, 110 (2006) 20546-20554.

[22] R.J. Wilson and R.P. Danner, J. Chem. Eng. Data, 28 (1983) 14-18.

[23] J.A. Ritter and R.T. Yang, Ind. Eng. Chem. Res., 26 (1987) 1679-1686.

[24] E. Buss, H. Ilmer, and M. Heuchel, Proceedings of Fundamentals of Adsorption, Elsevier, 1998, pp. 291-296.

[25] S. Couck, J.F.M. Denayer, G.V. Baron, T. Remy, J. Gascon, and F. Kapteijn, J. Am. Chem. Soc., 131 (2009) 6326. 
[26] J. Perez-Pellitero, H. Amrouche, F.R. Siperstein, G. Pirngruber, C. Nieto-Draghi, G. Chaplais, A. Simon-Masseron, D. Bazer-Bachi, D. Peralta, and N. Bats, Chem. Eur. J., 16 (2010) 1560-1571. 


\section{Figure Captions}

Figure 1 : representation of the structure of ZIF-76 with LTA topology

Figure 2 : XRD patterns of the ZIF-76 materials synthesized in DMF (sample 1, blue), DMF/DEF (sample 2, red) and simulated (black)

Figure 3 : XRD patterns of ZIF-76 materials synthesized with different quantities of base.

Figure 4 : SEM pictures of ZIF-76 synthesised with different B/L ratios : a/ 0, b / 0.5, c/ 1 and d/ 2.

Figure 5 : XRD patterns of new isomorphs of ZIF-76 and the original structure of ZIF-76 compared with the simulated pattern

Figure 6 : TGA of ZIF-76 isomorphs

Figure $7:{ }^{1 \mathrm{H}} \mathrm{NMR}$ spectra of ZIF-76 isomorphs $\mathrm{M}(\mathrm{Im})_{\mathrm{x}}(\mathrm{XbIM})_{\mathrm{y}}$ after digestion

Figure $8:$ a) $\mathrm{CO} 2$ and b) $\mathrm{CH} 4$ isotherms of adsorption of ZIF-76 isomorphs

Figure 9 : Breakthrough curves of $\mathrm{CO} 2$ and $\mathrm{CH} 4$ on ZIF-76 (Zn(Im)1.25(5-ClbIm)0.75) at 30 and 1 bar. 

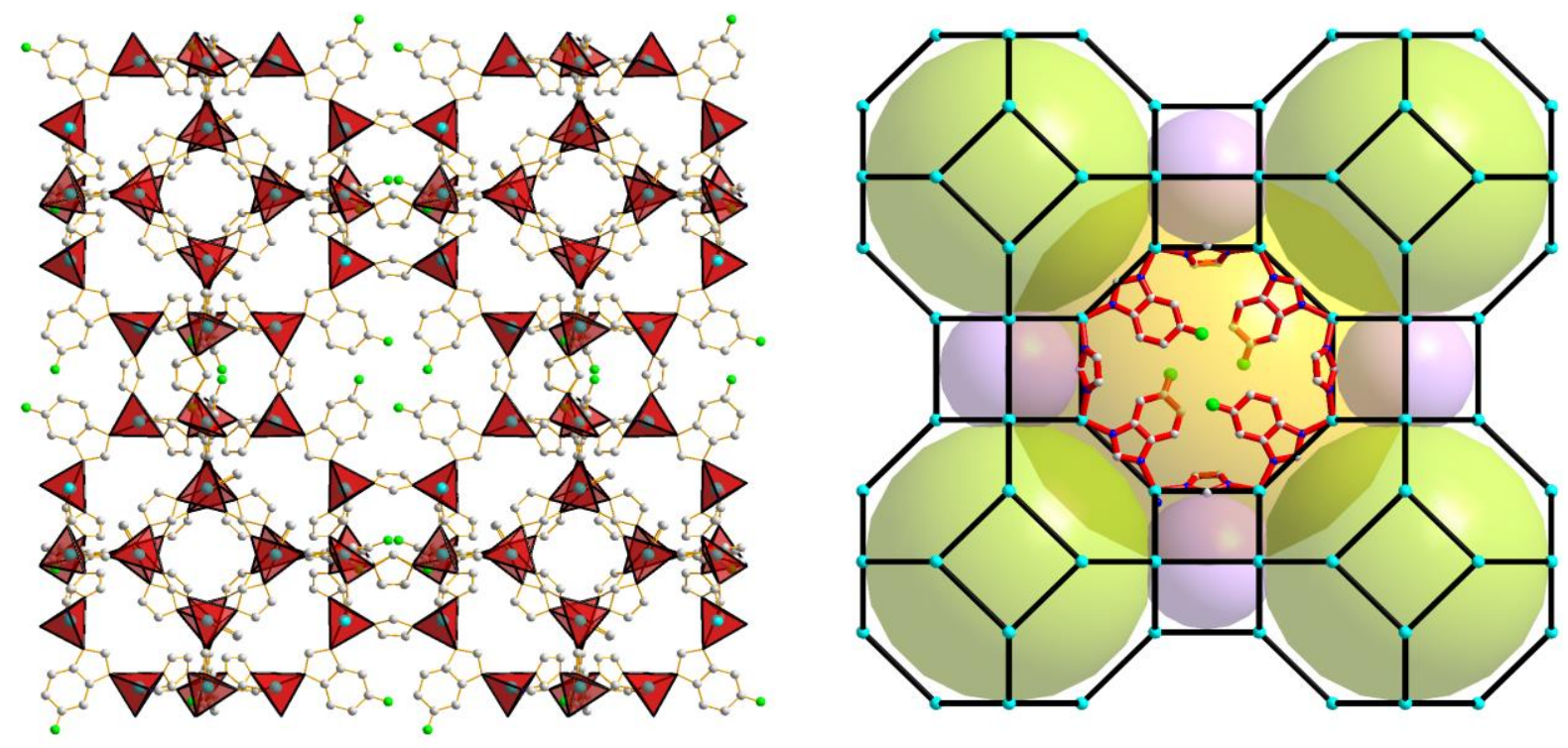

Figure 1 : representation of the structure of ZIF-76 with LTA topology

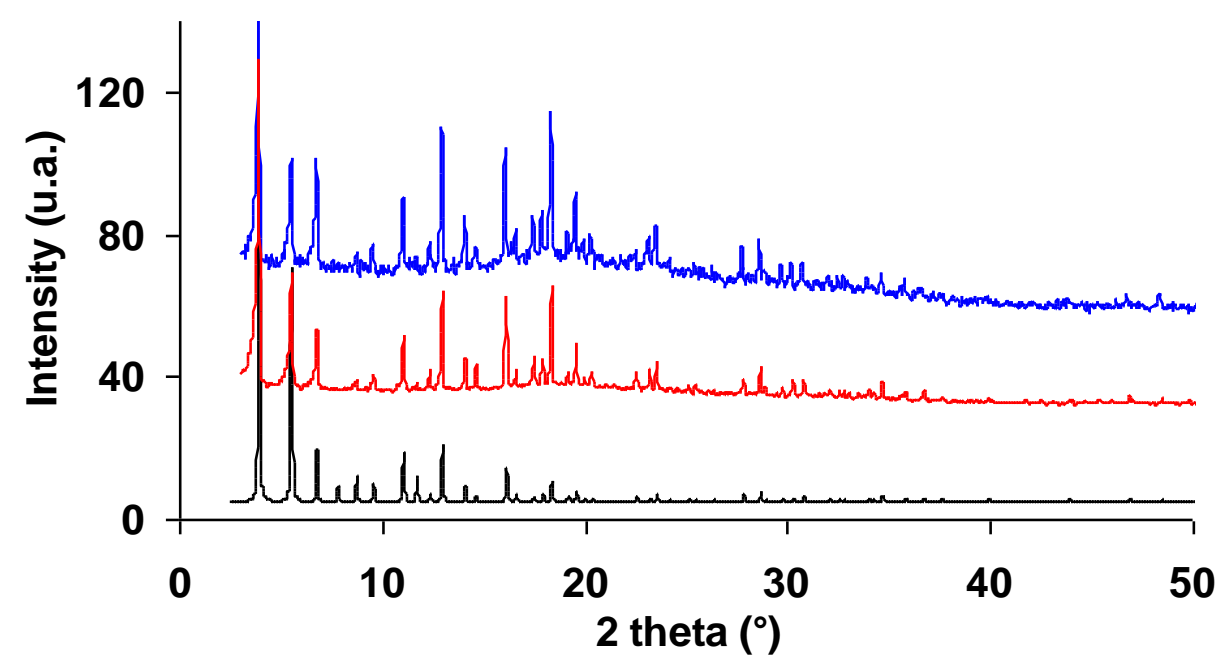

Figure 2 : XRD patterns of the ZIF-76 materials synthesized in DMF (sample 1, blue), DMF/DEF (sample 2, red) and simulated (black) 


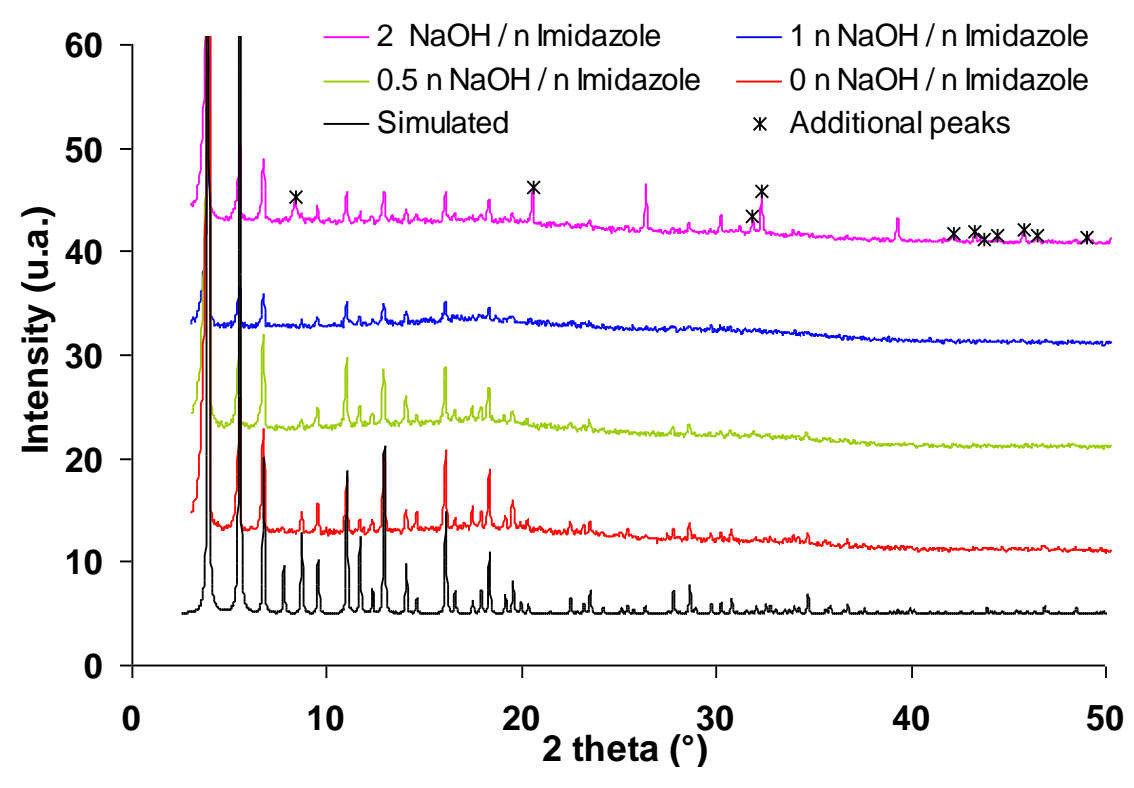

Figure 3 : XRD patterns of ZIF-76 materials synthesized with different quantities of base.
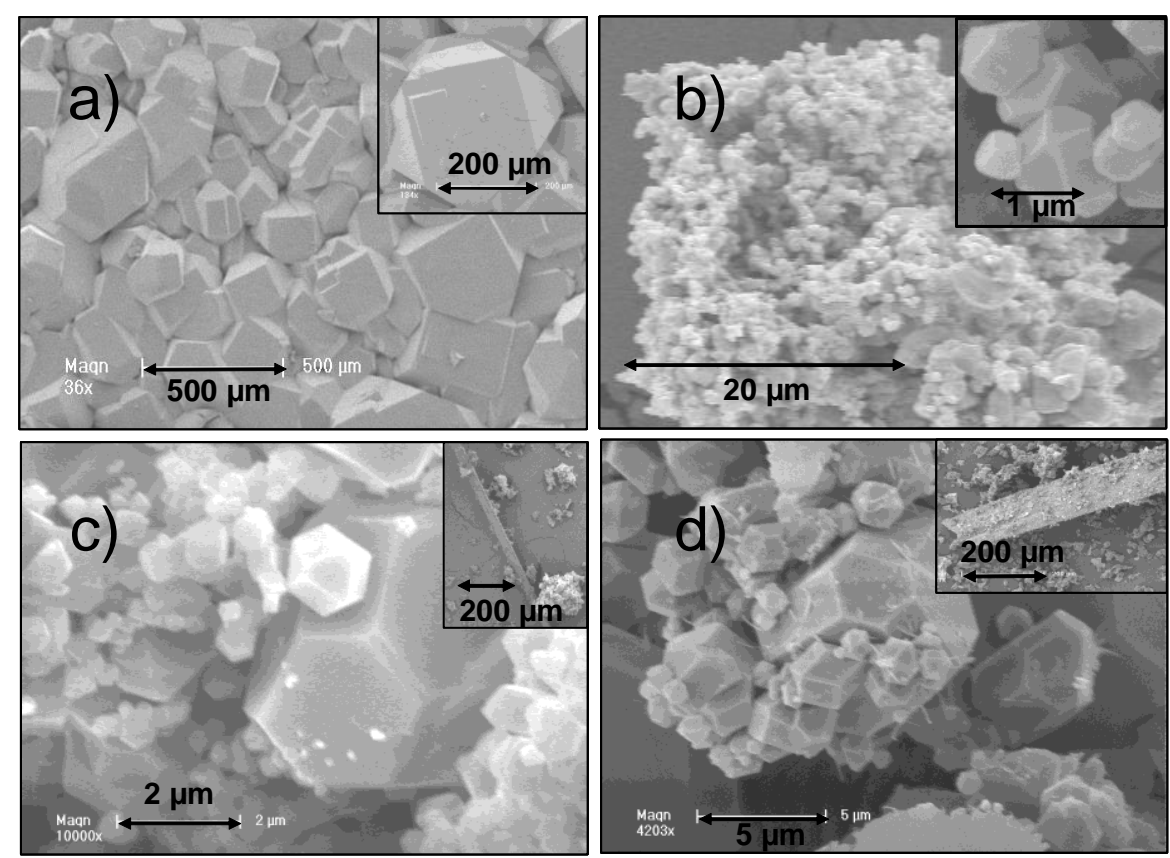

Figure 4 : SEM pictures of ZIF-76 synthesised with different B/L ratios : a/ 0, b / 0.5, c/ 1 and $\mathrm{d} / 2$. 


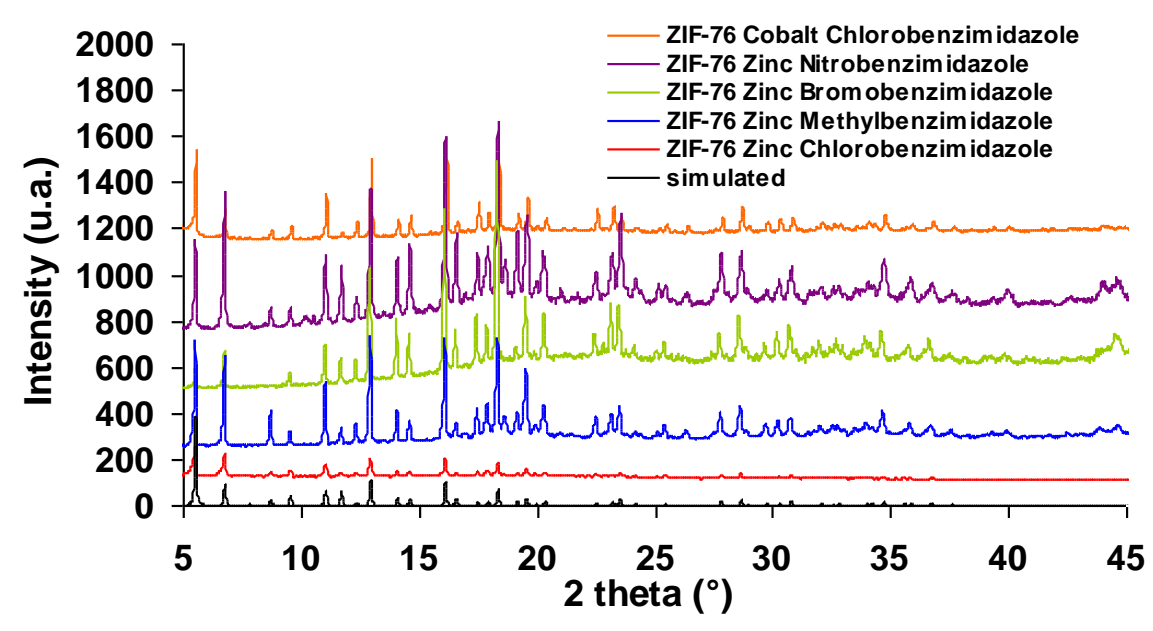

Figure 5 : XRD patterns of new isomorphs of ZIF-76 and the original structure of ZIF-76 compared with the simulated pattern

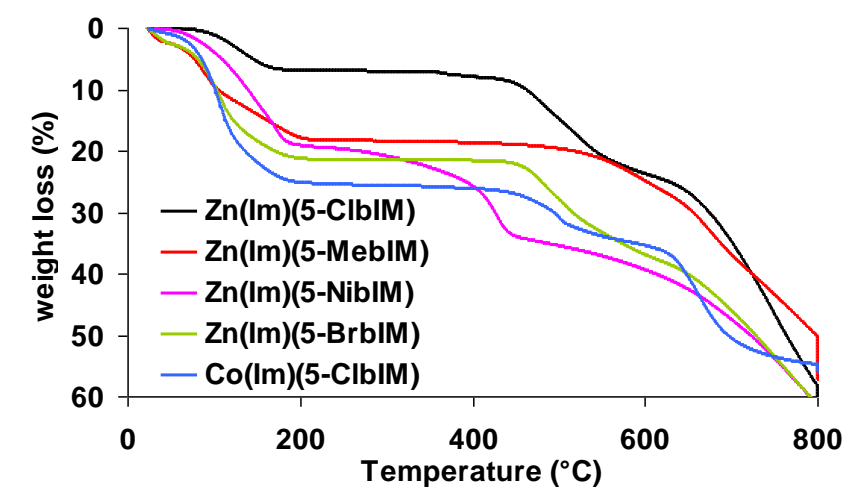

Figure 6 : TGA of ZIF-76 isomorphs 


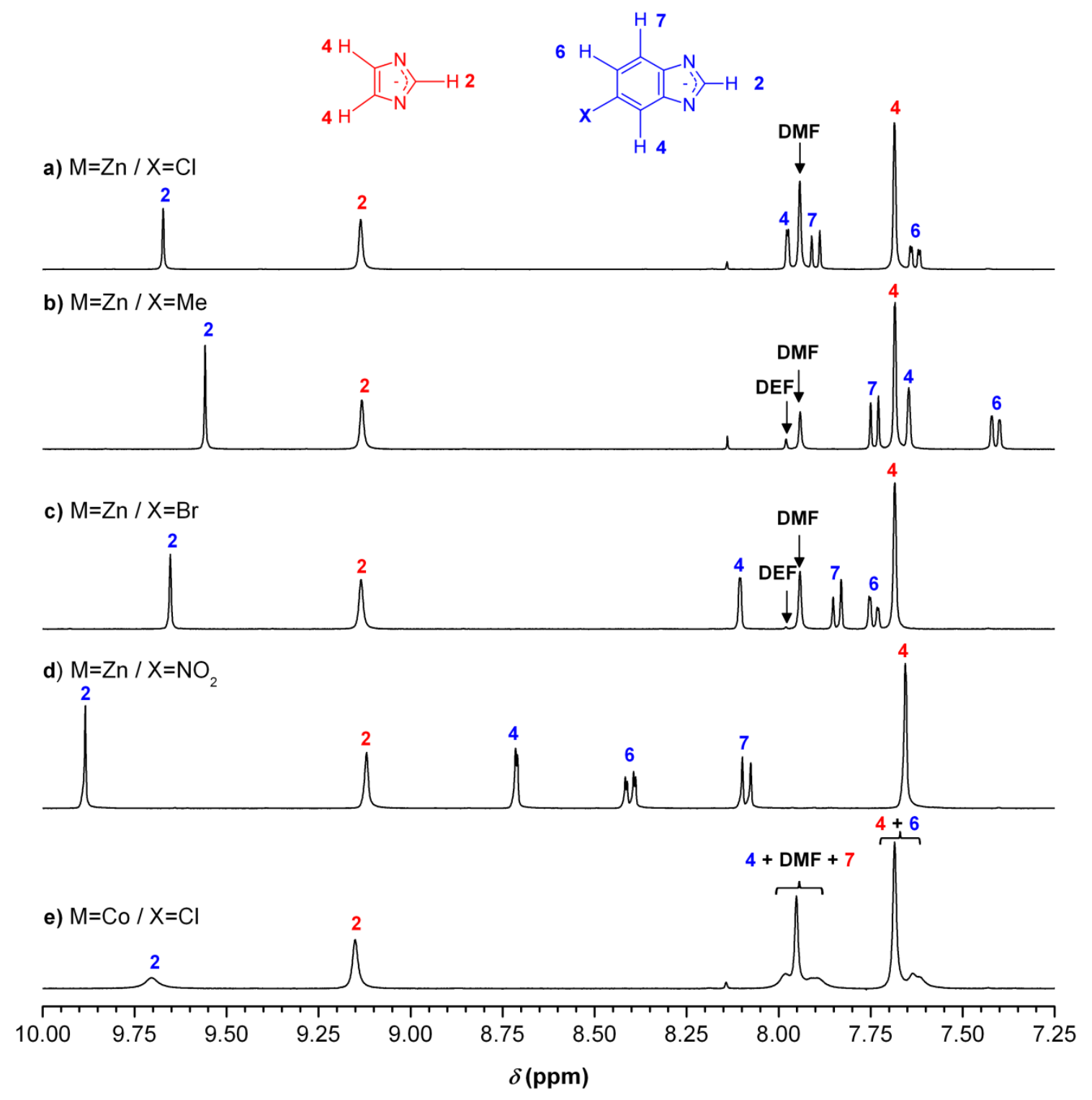

Figure $7:{ }^{1} \mathrm{H}$ NMR spectra of ZIF-76 isomorphs $\mathrm{M}(\mathrm{Im})_{\mathrm{x}}(\mathrm{XbIM})_{\mathrm{y}}$ after digestion 

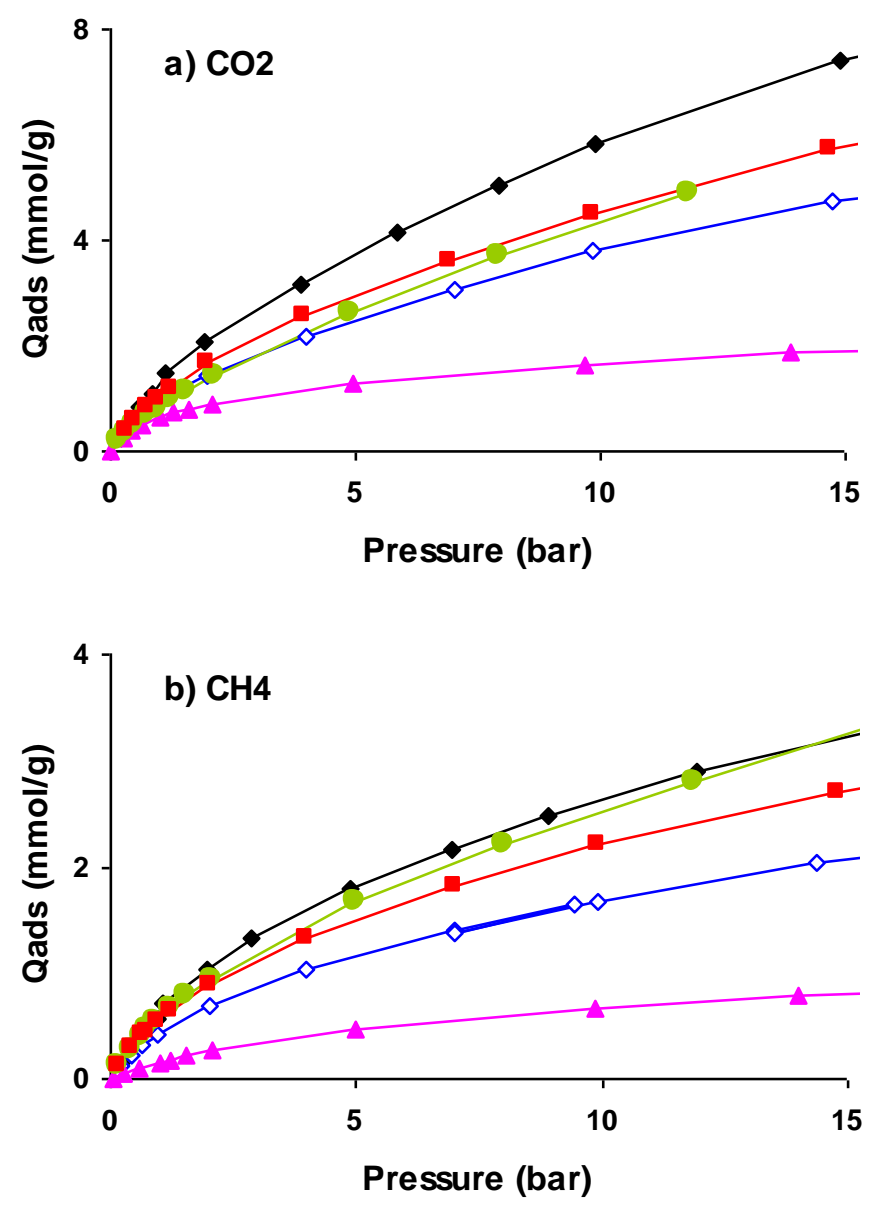

Figure $8:$ a) $\mathrm{CO}_{2}$ and b) $\mathrm{CH}_{4}$ isotherms of adsorption of ZIF-76 isomorphs: $\mathrm{Zn}(\mathrm{Im})_{1.25}(5-$ ClbIM $)_{0.75}$ full diamonds; $\mathrm{Co}(\mathrm{Im})_{1.3}(5 \text {-ClbIM) })_{0.7}$ open diamonds; $\mathrm{Zn}(\mathrm{Im})_{1.2}(5 \text {-BrbIM })_{0.8}$ circles; $\mathrm{Zn}(\operatorname{Im})_{1.1}(5-\mathrm{MebIM})_{0.9}$ squares; $\mathrm{Zn}(\operatorname{Im})_{1.05}(5-\mathrm{NibIM})_{0.95}$ triangles.

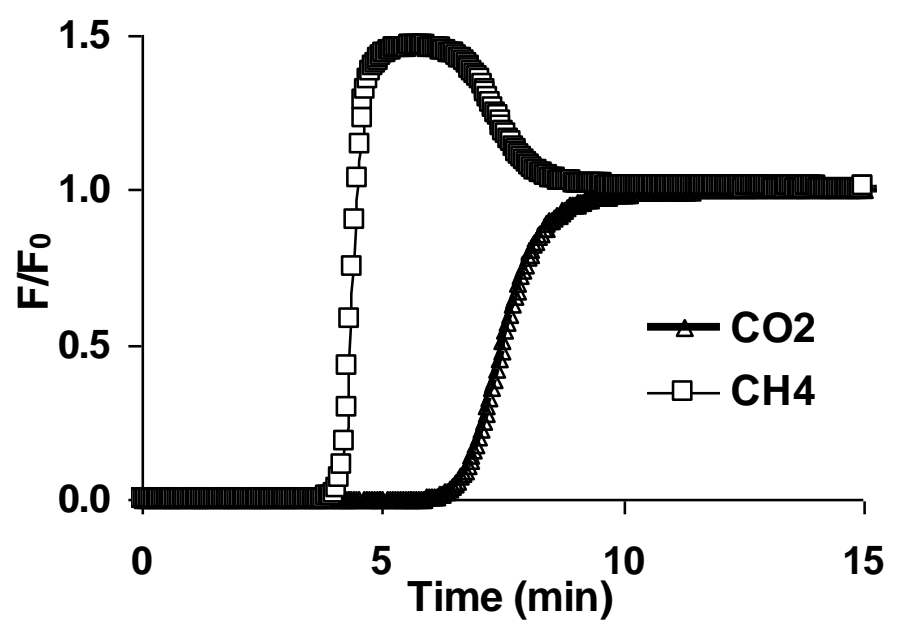

Figure 9 : Breakthrough curves of $\mathrm{CO}_{2}$ and $\mathrm{CH}_{4}$ on $\mathrm{ZIF}-76\left(\mathrm{Zn}(\mathrm{Im})_{1.25}(5-\mathrm{ClbIm})_{0.75}\right)$ at $30^{\circ}$ and 1 bar. 


\section{TABLES}

Table 1. Summary of the different synthesis conditions of ZIF-76 applied in this work

\begin{tabular}{|c|c|c|c|c|c|c|c|c|}
\hline Run & $\begin{array}{l}\text { Temperature } \\
\left({ }^{\circ} \mathrm{C}\right)\end{array}$ & $\begin{array}{l}\text { Duration } \\
\text { (days) }\end{array}$ & $\begin{array}{l}\mathrm{n} \mathrm{Im}{ }^{\mathrm{a}} \\
\left(10^{-4} \text { moles }\right)\end{array}$ & $\begin{array}{l}\text { n 5-ClbIm }{ }^{b} \\
\left(10^{-4} \text { moles }\right)\end{array}$ & $\begin{array}{l}\mathrm{n} \mathrm{Zn}\left(\mathrm{NO}_{3}\right)_{2} \\
\left(10^{-4} \text { moles }\right)\end{array}$ & $\begin{array}{l}\text { n DMF } \\
\left(10^{-4} \text { moles }\right)\end{array}$ & $\begin{array}{l}\mathrm{n} \text { DEF } \\
\left(10^{-4} \text { moles }\right)\end{array}$ & $\begin{array}{l}\mathrm{n} \mathrm{NaOH} \\
\left(10^{-4} \text { moles }\right)\end{array}$ \\
\hline 1 & 70 & 5 & 8.63 & 4.33 & 4.29 & 1485 & 0 & 0 \\
\hline 2 & 70 & 5 & 8.63 & 4.33 & 4.29 & 743 & 516 & 0 \\
\hline 3 & 70 & 5 & 17.25 & 8.66 & 8.59 & 743 & 516 & 0 \\
\hline 4 & 90 & 5 & 8.63 & 4.33 & 4.29 & 743 & 516 & 0 \\
\hline 5 & 90 & 5 & 17.25 & 8.66 & 8.59 & 743 & 516 & 0 \\
\hline 6 & 90 & 5 & 17.25 & 8.66 & 8.59 & 743 & 516 & 12.96 \\
\hline 7 & 90 & 5 & 17.25 & 8.66 & 8.59 & 743 & 516 & 25.91 \\
\hline 8 & 90 & 5 & 17.25 & 8.66 & 8.59 & 743 & 516 & 51.83 \\
\hline 9 & 90 & 30 & 17.25 & 8.66 & 8.59 & 743 & 516 & 0 \\
\hline 10 & 90 & 30 & 17.25 & 8.66 & 8.59 & 743 & 516 & 12.96 \\
\hline 11 & 90 & 30 & 17.25 & 8.66 & 8.59 & 743 & 516 & 25.91 \\
\hline 12 & 90 & 30 & 17.25 & 8.66 & 8.59 & 743 & 516 & 51.83 \\
\hline
\end{tabular}

${ }^{\mathrm{a}}$ Im =imidazole, b ClbIM = chlorobenzimidazole

Table 2. Crystal size as function of the quantity of $\mathrm{NaOH}$ used in the synthesis.

\begin{tabular}{|l|l|l|l|}
\hline Run & $\begin{array}{l}\text { Synthesis time } \\
(\text { days })\end{array}$ & $\frac{\mathrm{n}_{\text {NaOH }}}{\mathrm{n}_{\text {Imidazoles }}}$ & $\begin{array}{l}\text { Average crystal size } \\
(\mu \mathrm{m})\end{array}$ \\
\hline 5 & 5 & 0 & 57.0 \\
\hline 6 & 5 & 0.5 & 1.2 \\
\hline 9 & 30 & 0 & 232.0 \\
\hline 10 & 30 & 0.5 & 0.8 \\
\hline
\end{tabular}

Table 3. Composition of the ZIF-76 isomorphs deduced from NMR analysis

\begin{tabular}{|l|l|l|l|l|}
\hline Metal source & Ligand 1 & Ligand 2 & Formula of the materials & Im/XbIm \\
\hline $\mathrm{Zn}\left(\mathrm{NO}_{3}\right)_{2} \cdot 6 \mathrm{H}_{2} \mathrm{O}$ & $\mathrm{Im}$ & 5-ClbIm & $\mathrm{Zn}(\mathrm{Im})_{1.25}(5 \text {-ClbIM })_{0.75}(\mathrm{DMF})_{1.5}(\mathrm{DEF})_{0.02}$ & 1.7 \\
\hline $\mathrm{Co}\left(\mathrm{NO}_{3}\right)_{2} \cdot 6 \mathrm{H}_{2} \mathrm{O}$ & $\mathrm{Im}$ & 5 -ClbIm & $\mathrm{Co}(\mathrm{Im})_{1.3}(5 \text {-ClbIM })_{0.7}(\mathrm{DMF})_{1.4}$ & 1.8 \\
\hline $\mathrm{Zn}\left(\mathrm{NO}_{3}\right)_{2} \cdot 6 \mathrm{H}_{2} \mathrm{O}$ & $\mathrm{Im}$ & 5-BrbIm & $\mathrm{Zn}(\mathrm{Im})_{1.2}(5 \text {-BrbIM })_{0.8}(\mathrm{DMF})_{0.9}(\mathrm{DEF})_{0.03}$ & 1.4 \\
\hline $\mathrm{Zn}\left(\mathrm{NO}_{3}\right)_{2} \cdot 6 \mathrm{H}_{2} \mathrm{O}$ & $\mathrm{Im}$ & 5 -MebIm & $\mathrm{Zn}(\mathrm{Im})_{1.1}(5-\mathrm{MebIM})_{0.9}(\mathrm{DMF})_{0.54}(\mathrm{DEF})_{0.11}$ & 1.2 \\
\hline $\mathrm{Zn}\left(\mathrm{NO}_{3}\right)_{2} \cdot 6 \mathrm{H}_{2} \mathrm{O}$ & $\mathrm{Im}$ & 5-NibIm & $\mathrm{Zn}(\mathrm{Im})_{1.05}(5-\mathrm{NibIM})_{0.95}$ & 1.1 \\
\hline
\end{tabular}


Table 4. Adsorption properties of the ZIF-76 isomorphs: BET surface area, micropore volume, Henry constants of $\mathrm{CO}_{2}$ and $\mathrm{CH}_{4}$ at $303 \mathrm{~K}$, ratio of the Henry constants and $\mathrm{CO}_{2} / \mathrm{CH}_{4}$ selectivity obtained from breakthrough curves.

\begin{tabular}{|c|c|c|c|c|c|c|}
\hline Materials & $\begin{array}{l}\mathrm{S}_{\mathrm{BET}} \\
\mathrm{m}^{2} \cdot \mathrm{g}^{-1}\end{array}$ & $\begin{array}{l}\mathrm{V} \mu \\
\mathrm{cm}^{3} \cdot \mathrm{g}^{-1}\end{array}$ & $\begin{array}{l}\mathrm{K}_{\text {Henry }} \mathrm{CO}_{2} \\
\mathrm{mmol} \cdot \mathrm{g}^{-1} \cdot \mathrm{bar}^{-1}\end{array}$ & $\begin{array}{l}\mathrm{K}_{\text {Henry }} \mathrm{CH}_{4} \\
\text { mmol.g }{ }^{-1} \cdot \text { bar }^{-1}\end{array}$ & $\begin{array}{l}\mathrm{K}_{\text {Henry }} \mathrm{CO}_{2} / \\
\mathrm{K}_{\text {Henry }} \mathrm{CH}_{4}\end{array}$ & $\begin{array}{l}\text { Selectivity } \\
\mathrm{CO}_{2} / \mathrm{CH}_{4}\end{array}$ \\
\hline $\mathrm{Zn}(\mathrm{Im})_{1.25}(5-\mathrm{ClbIM})_{0.75}$ & 1561 & 0.60 & 1.52 & 0.75 & 2.0 & 2.3 \\
\hline $\mathrm{Co}(\mathrm{Im})_{1.3}(5-\mathrm{ClbIM})_{0.7}$ & 1097 & 0.42 & 1.13 & 0.52 & 2.2 & 2.4 \\
\hline $\mathrm{Zn}(\operatorname{Im})_{1.2}(5-\mathrm{BrbIM})_{0.8}$ & 1050 & 0.40 & 0.97 & 0.69 & 1.4 & 2.7 \\
\hline $\mathrm{Zn}(\operatorname{Im})_{1.1}(5-\mathrm{MebIM})_{0.9}$ & 1536 & 0.58 & 1.18 & 0.67 & 1.8 & 2.4 \\
\hline $\mathrm{Zn}(\operatorname{Im})_{1.05}(5-\mathrm{NibIM})_{0.95}$ & 850 & 0.32 & 0.98 & 0.18 & 5.5 & 6.5 \\
\hline
\end{tabular}

